\title{
Darf die Therapie gegen Aufpreis verlängert werden?
}

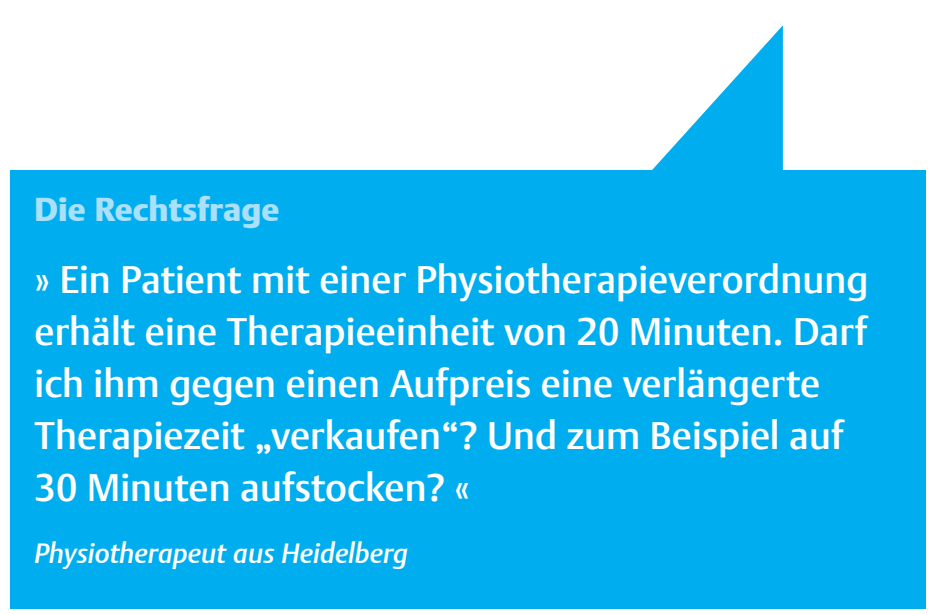

\section{Die Antwort unseres Experten}

Wie so oft lautet auch hier die Antwort: Es kommt darauf an. Und zwar darauf, wer Zahlungen verlangt und vor allem wie dies geschieht.

Private Zuzahlungen zu Rezepten sind verboten. Dies ergibt sich bereits aus $\S 21$ der gemeinsamen Rahmenempfehlungen. Darin steht, dass Physiotherapeuten für erbrachte Leistungen mit Ausnahme der gesetzlichen Zuzahlung des Versicherten keine weiteren Zuzahlungen fordern dürfen. $\S 3$ der Heilmittelrichtlinie untermauert dieses Verbot. Laut Absatz 1 ist ein Physiotherapeut an die Verordnung gebunden. Er darf also nur die verordnete Leistung erbringen, für die beispielsweise im Rahmen der krankengymnastischen Behandlung 15 bis 25 Minuten angesetzt sind. Darüber hinausgehende Erweiterungen sind unzulässig und können zu Regressen führen.

Als Physiotherapeut haben Sie also keine Möglichkeiten, die Therapiezeit einer Verordnung gegen Aufpreis zu verlängern. Dies gilt sowohl für einzelne Therapieeinheiten als auch für das Rezept. Sie dürfen keine weiteren Behandlungen „verkaufen“. Denn: Erbringt ein Physiotherapeut weitergehende Behandlungen, für die keine ärztliche Verordnung vorliegt, verstößt er gegen das Heilpraktikergesetz.

Erlaubt ist eine Anschlussbehandlung außerhalb des Rezepts, beispielsweise Massagen. Hierfür benötigt ein Patient keine Verordnung. Auch einer verordneten Behandlung kann sich eine privat verkaufte Massage anschließen. Dies hat dann nichts mit der Verordnung zu tun. Physiotherapeuten müssen hierbei allerdings die Umsatzsteuerpflichtigkeit derartiger Behandlungen beachten.

Wesentlich einfacher gestaltet sich die Rechtslage, wenn ein Therapeut Heilpraktiker oder sektoraler Heilpraktiker ist. In diesem Fall kann er selbst - auch ohne ärztliche Verordnung - tätig werden. Er darf zusätzliche Leistungen erbringen, für die ein Patient privat aufkommt. Er muss allerdings darauf achten, dass er sich nicht in Widerspruch zu den Rahmenempfehlungen setzt. Das heißt, dass die abgege- benen Heilmittel aufgrund der Verordnung und als Selbstzahlerleistung klar voneinander abgegrenzt sein müssen. So wäre es etwa möglich, die ärztliche Verordnung in dem vorgesehenen Zeittakt abzuarbeiten und anschließend aufgrund eigener Verordnung als Heilpraktiker zusätzliche Leistungen zu erbringen. Diese rechnet man dann komplett getrennt von dem Rezept und der hierauf bezogenen Zuzahlung privat ab.

Philipp Groteloh

\section{$\rightarrow$ Wirft auch Ihr Berufsalltag rechtliche Fragen auf? Dann schreiben Sie an Simone.Gritsch@thieme.de.}

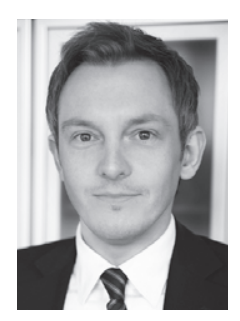

Dr. Philipp Groteloh ist seit 2007 Rechtsanwalt und seit 2012 Fachanwalt für Verwaltungsrecht. 